\title{
O silêncio de grupos específicos de crianças em pesquisas ${ }^{1}$
}

\section{Silence of specific groups of children in researches}

\author{
Renata Lopes Costa Prado ${ }^{2}$
}

\begin{abstract}
RESUMO
Temos assistido, pouco a pouco, a ampliação do espaço outorgado à voz das crianças em pesquisas das ciências sociais e humanas, embora historicamente elas tenham tido seu direito de falar negado, por serem vistas como incompetentes para julgar e informar adequadamente. $\mathrm{O}$ artigo discute como a perspectiva delas vem sendo incorporada na pesquisa brasileira, dando especial ênfase à caracterização das crianças envolvidas. Analisou-se 179 artigos de antropologia, educação, psicologia e sociologia que relatam pesquisas com crianças, publicados entre 2000 e 2012, em periódicos classificados como A1 ou A2, pela Coordenação de Aperfeiçoamento de Pessoal de Nível Superior (CAPES). Crianças pequenas, que vivem na zona rural e/ou nas regiões Norte, Nordeste e Centro-Oeste permanecem silenciadas. São ausências com importantes repercussões teóricas e políticas.
\end{abstract}

Palavras-chave: crianças; pesquisa; estudos sociais da infância.

\begin{abstract}
Gradually, we have seen the expansion of space granted to the voice of children in researches on social and human sciences, although historically they have disregarded children's voice, because they were seen as incompetent to judge or properly inform. The article discusses how their perspective has been incorporated in Brazilian research, with special emphasis on the
\end{abstract}

DOI: $10.1590 / 0104-4060.48216$

1 Artigo elaborado a partir da tese de doutorado A participação de crianças em pesquisas das ciências sociais e humanas (2014), desenvolvida no Instituto de Psicologia da Universidade de São Paulo, com financiamento da Coordenação de Aperfeiçoamento de Pessoal de Nível Superior.

2 Universidade Federal Fluminense. Instituto de Educação de Angra dos Reis. Angra dos Reis, Rio de Janeiro, Brasil. Av. do Trabalhador, nº 179, Verolme. CEP: 23914-360. E-mail: renata. lopescp@gmail.com 
characterization of the children involved. We have analyzed 179 research report articles of anthropology, education, psychology and sociology with the involvement of children that were published between 2000 and 2012 in journals classified as A1 or A2 by the Coordination for the Improvement of Higher Education Personnel (CAPES). Young children, living in non-urban areas or located in the North, Northeast and Midwest remain silenced. There is this absence with important theoretical and political repercussion.

Keywords: children; research; social studies of childhood.

Historicamente, as crianças ${ }^{3}$ tiveram seu direito de falar por si mesmas negado nas pesquisas por serem tidas como incompetentes para fazerem julgamentos e por não serem vistas como informantes adequadas, nem mesmo em relação às suas próprias vidas. (LEE, 2010). Além disso, quando ouvidas, suas vozes, em geral, foram interpretadas à luz dessa suposta incompetência, como no caso dos trabalhos de Piaget, inovadores para a época, por incentivar as crianças a falarem livremente, mas marcados pela crença de que o distanciamento da razão diferenciaria fundamentalmente as crianças dos adultos. (JENKS, 2002).

Em anos recentes, no entanto, pesquisadores têm proposto, cada vez mais, entender a infância - e não só ela - sob a ótica das crianças. (CORSARO, 2005; PRADO, 2013). A ampliação do espaço outorgado à voz das crianças nas pesquisas acadêmicas constitui, por um lado, uma conquista para elas. Por outro, provoca consequências nas pesquisas em geral, pois não se trata apenas de ampliar o número de pessoas ouvidas, mas de considerar outros saberes e de contemplar perspectivas que se diferenciam daquelas dos adultos pesquisadores.

Assim, autores como Corsaro (2005) identificam que há pouco mais de duas décadas foi iniciado, em diferentes países, um movimento geral que se configura pela passagem do pesquisar as crianças, caracterizado, principalmente, pela avaliação delas, para o pesquisar com ou para as crianças. No Brasil, apesar de tal movimento ser mais recente (DELGADO; MARCHI, 2007), nos últimos anos tem sido publicada uma significativa produção sobre a participação de crianças nas pesquisas. (MARTINS FILHO; PRADO, 2011; MÜLLER, 2010; FARIA; DEMARTINI; PRADO, 2009; CASTRO; BESSET, 2008, entre outros).

A emergência desse novo modo de encarar as crianças na produção acadêmica justifica-se por fatores políticos e sociais, bem como por aspectos teóricos. No plano social e político, ela pode ser vista como resultado de transformações mais amplas de práticas institucionais. Prout (2010) argumenta que por conta

3 Em consonância com a Convenção Internacional sobre os Direitos da Criança, o termo crianças aqui é usado em sentido amplo, referindo-se a todo ser humano menor de 18 anos de idade. 
de rápidas e profundas mudanças sociais, instituições foram fragmentadas e deixaram de ser tomadas como sólidas e certas, o que teve como importante consequência a introdução de "técnicas de reflexividade" nas práticas institucionais, ou seja, um conjunto de atores sociais passou a ser convocado a participar expressando suas considerações, opiniões e interesses.

A legislação relacionada à infância compõe também este processo: direitos de participação passaram a ser atribuídos às crianças pela Convenção Internacional sobre os Direitos da Criança, proclamada pela Organização das Nações Unidas em 1989, que reconhece à criança os direitos e as liberdades inscritas na Declaração dos Direitos Humanos.

No plano teórico, a preocupação de pesquisadores em ouvir o que as crianças têm a dizer pode ser descrita como consequência da releitura do conceito de socialização e da ênfase no ator, que caracterizou o movimento, desenvolvido a partir da década de 1970, de redescoberta da sociologia interacionista, de aumento da influência da fenomenologia e de consolidação das abordagens construcionistas. (SIROTA, 2001). Pesquisadores, de diferentes áreas, voltaram seu interesse para os modos pelos quais a vida social é apreendida, e não apenas ordenada. A realidade concreta passa a ser vista neste contexto como "[...] mais que fatos ou dados tomados mais ou menos em si mesmos. Ela é todos esses fatos e todos esses dados e mais a percepção que deles esteja tendo a população neles envolvida". (FREIRE, 1981, p. 35).

Foi nesse clima intelectual que se originaram os estudos sociais da infância, que, desde o início dos anos 1980, vêm trazendo profundas transformações para o modo de se olhar a infância e as crianças, bem como para a eleição de estratégias para estudá-las que as privilegiem como unidade primária de análise. Os paradigmas propostos pelos estudos sociais da infância originam-se, principalmente, da sociologia, apesar de orientarem também pesquisas nas áreas de antropologia, educação, história, geografia, economia, direito e psicologia.

A fala da criança, historicamente desconsiderada, passa a ser vista, então, como a fala de um ator legítimo e competente. Os estágios do desenvolvimento que vinculam excessivamente competência à idade são problematizados por seu viés adultocêntrico, já que, como afirma Jenks (2002), eles habitualmente têm servido para avaliar crianças em termos da sua maior ou menor competência frente ao padrão adulto, enquanto se ignora a prática social da criança, com sua estrutura de significados própria e coerente.

Sem negar que seres humanos se desenvolvem ao longo do tempo por meios descritíveis ou que comportamentos sociais apropriados não são naturais, mas aprendidos, o paradigma da competência busca tomar as 
crianças como agentes sociais por direito próprio; examinar como construções sociais sobre "infância" não apenas estruturam suas vidas como são estruturadas pelas próprias crianças; e explicar competências sociais que crianças manifestam no curso de suas vidas cotidianas como crianças, com outras crianças e com adultos. (HUTCHBY; MORAN-ELLIS, 1998, p. 8, tradução nossa).

Hutchby e Moran-Ellis (1998) destacam três importantes aspectos a serem levados em conta pelos estudos que assumem as competências das crianças: (1) a busca por um ponto de vista de "dentro" para compreender as ações sociais das crianças; (2) a contextualização dos estudos sobre essas competências em circunstâncias empíricas da vida cotidiana das crianças; e (3) o reconhecimento de que tais circunstâncias, ou arenas de ação, podem tanto constranger quanto favorecer a capacidade das crianças de mostrar suas competências sociais. De fato, como eles lembram, o que se observa é que a institucionalização de estruturas particulares de poder acaba por privilegiar a competência (e a ação) de certos atores, em detrimento de outros, o que ajuda a entender o silenciamento de crianças em sociedades centradas nos adultos. É este o caso da sociedade ocidental moderna, em que hierarquias etárias constituem um dos eixos das desigualdades sociais (ao lado de gênero, raça e classe).

Considerando, assim, que as crianças compartilham entre si uma posição subordinada na sociedade pelo simples fato de serem crianças e que, simultaneamente, diferenciam-se umas das outras por suas pertenças étnico-raciais, de classe, de gênero, de nacionalidade, etc., há, no âmbito dos estudos sociais da infância, um embate recorrente (e instigante) entre autores alinhados ao enfoque estrutural e autores que assumem uma abordagem interpretativa: os primeiros defendem que se privilegie o recorte geracional como categoria analítica apontando para características estruturais comuns a todas as crianças, em detrimento da diversidade de contextos em que crianças vivem a infância (ver QVORTRUP, 2010); os últimos, ao contrário, tendem a acentuar a pluralidade de "infâncias", considerando particularidades que conformam as vidas de crianças em diferentes contextos e sociedades. A esse respeito, concordo com James (2007, p. 266), quando ela afirma que "[...] a necessidade de reconhecer que as diversidades que distinguem uma criança de outra são tão importantes e tão significativas quanto as semelhanças que possam compartilhar".

Tomando a academia como um ator privilegiado na construção de discursos e na arena de negociação de políticas para a infância, a pesquisa que deu origem a este texto discute entraves e avanços que caracterizam a escuta de crianças nas pesquisas, observando, quando possível, como ela diverge da escuta de 
outros grupos etários. Analisam-se também os espaços diferenciados que têm sido abertos a grupos de crianças de contextos diversos e atravessados por diferentes marcadores sociais. É sobre este aspecto que trata o presente artigo: quando falamos em ouvir as crianças, falamos de todas elas? Se não, de quais?

\section{Percurso metodológico}

O corpus analisado pelo estudo compreendeu os artigos acadêmicos que atendem aos seguintes critérios: relatar pesquisa com a participação de crianças desenvolvida no Brasil contemporâneo, que não tenha o objetivo explícito de avaliá-las; ter sido publicado por uma revista brasileira classificada como Qualis A1 ou A2 (triênio 2010-2012), que abranja várias áreas de conhecimento ou que seja especializada nas áreas da psicologia, educação, antropologia ou sociologia; ter, pelo menos, um dos autores graduados em uma destas áreas; e estar integralmente disponível na internet. Definiu-se os anos entre 2000 e 2012 como recorte temporal para a publicação dos artigos, levando-se em consideração a emergência dos estudos sociais da infância no país no início da última década. Após a realização de buscas de artigos utilizando os abrangentes descritores "criança" e/ou "infância" nos 65 periódicos que atendem aos critérios estabelecidos, levantou-se 1.580 artigos. Seus títulos, resumos e alguns trechos foram lidos para verificar se estavam de acordo com os critérios do corpus. Quando os artigos não apresentavam o currículo resumido dos autores, eles foram pesquisados na Plataforma Lattes para assegurar que tais autores vinham de uma das quatro áreas enfocadas pela pesquisa. Assim, 179 artigos foram selecionados para compor o corpus da pesquisa.

O procedimento de escolha dos textos, focalizando quatro áreas de conhecimento e restringindo o veículo de publicação às revistas mais bem classificadas pela Coordenação de Aperfeiçoamento de Pessoal de Nível Superior (CAPES), ao mesmo tempo em que permitiu estabelecer um recorte, orientou-se para a produção acadêmica brasileira considerada de maior qualificação. Os artigos do corpus foram publicados por revistas consideradas de elevada qualidade: um contexto que possibilita a maior visibilidade dos temas tratados, bem como de suas abordagens.

As técnicas da análise de conteúdo, tal como sistematizadas por Bardin (2002), serviram de apoio para a descrição organizada e sistemática dos conteúdos dos textos analisados, destacando suas características estruturais, seus padrões e as interpretações propostas acerca da participação das crianças nas 
pesquisas. Os artigos foram categorizados, entre outros aspectos, de acordo com a área de conhecimento do estudo, o local e o ano de publicação, o local de realização da pesquisa, além de faixa etária, sexo, classe social e cor/raça das crianças envolvidas.

\section{Quais crianças são ouvidas?}

Há um impressionante crescimento do número de artigos do corpus publicado a cada ano (Figura 1), o que, em um primeiro momento, parece reforçar a ideia de que as crianças estão sendo cada vez mais ouvidas pelas pesquisas, como já haviam observado outros pesquisadores. (MASON, 2005; MARTINS FILHO; MARTINS, 2012).

\section{FIGURA 1 - DISTRIBUIÇÃO DOS ARTIGOS POR ANO DE PUBLICAÇÃO}

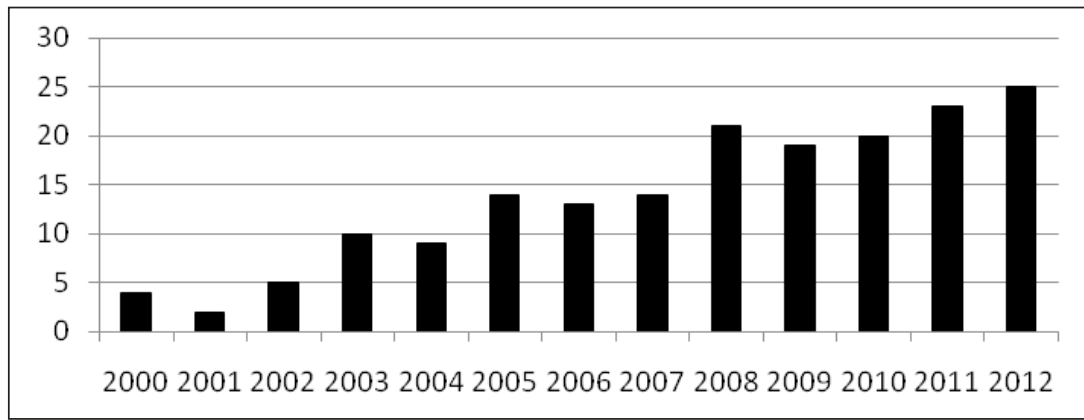

FONTE: Prado (2014).

Duas ressalvas, no entanto, precisam ser feitas acerca desses dados. A primeira é a de que o dado não deve ser interpretado apenas pelo viés das pesquisas sobre e com crianças e infância, pois os últimos anos têm assistido a um crescimento significativo da produção acadêmica em geral. A segunda ressalva é a de que nem todos os periódicos consultados para a constituição do corpus disponibilizam eletronicamente os artigos publicados no início da década de 2000, o que impacta no maior número de artigos na segunda metade do período analisado. De qualquer forma, se tomarmos apenas os anos posteriores a 2007, ano a partir do qual a totalidade das revistas pesquisadas oferece acesso digital aos artigos, é possível observar um crescimento de $10 \%$ ao ano no número de 
artigos que relatam pesquisas com o envolvimento de crianças. Considerando que as pesquisas podem anteceder vários anos à publicação dos artigos, é possível sugerir, com Nascimento e colaboradoras (2013), Martins Filho e Martins (2012) e Silva, Luz e Faria Filho (2010), que a emergência dos estudos sociais da infância no Brasil no início da década anterior tenha impactado os modos de pesquisar crianças e infância, com especial atenção à voz das crianças.

A escuta de crianças, no entanto, não se difundiu de forma homogênea entre as quatro áreas de conhecimento focalizadas pela pesquisa. Se, em anos recentes, sociólogos e antropólogos têm tido papel de destaque na produção acadêmica internacional com o envolvimento de crianças, isso não pode se afirmar em relação à produção brasileira. A concentração da produção acadêmica analisada na área de psicologia e a sua escassez na antropologia e na sociologia puderam ser observadas tanto em relação às áreas das revistas, quanto em relação à área de graduação dos autores. Mais da metade dos artigos (57,5\%) foi publicada em revistas de psicologia. O percentual de artigos publicados por revistas de educação também é significativo (36,9\%), mas nos pareceu baixo, pois o número de revistas de educação (49) consultadas é maior do que a soma das revistas avaliadas dentro das outras três áreas (16 da psicologia, 15 da sociologia e nove da antropologia) ${ }^{4}$.

Os periódicos de ciências sociais, ou os específicos de sociologia e de antropologia, praticamente não publicaram pesquisas com o envolvimento de crianças ao longo do recorte temporal focalizado. Dessas áreas, apenas dois periódicos aparecem como veículos de publicação de artigos do corpus, o Mana (Universidade Federal do Rio de Janeiro - UFRJ), alinhado editorialmente à antropologia social, com dois artigos publicados, e o periódico Novos Estudos (Centro Brasileiro de Análise e Planejamento - CEBRAP), orientado às ciências sociais em geral, com um artigo publicado.

Em relação à área de graduação de seus autores, 54,2\% dos artigos foram escritos exclusivamente por psicólogos, $13,4 \%$ por pedagogos e apenas $1,7 \%$ por pesquisadores graduados em ciências sociais - todos eles pós-graduados em antropologia. Outros 30,7\% contaram com a autoria de pesquisadores de mais de uma área. No total, foi possível verificar que 75,4\% dos artigos (135) contam com a autoria de psicólogos; $29 \%$ (52) contam com a autoria de pedagogos; e 6,1\% (11) com a autoria de cientistas sociais. Tal concentração na área da psicologia parece seguir, senão uma tendência de crescimento, ao menos de permanência (Figura 2).

4 A diferença entre os números de revistas consultadas por área corresponde à diferença entre os números de revistas brasileiras classificadas como A1 ou A2 pela CAPES nas quatro áreas. 
FIGURA 2 - DISTRIBUIÇÃO DOS ARTIGOS POR ÁREA DOS AUTORES E POR ANO

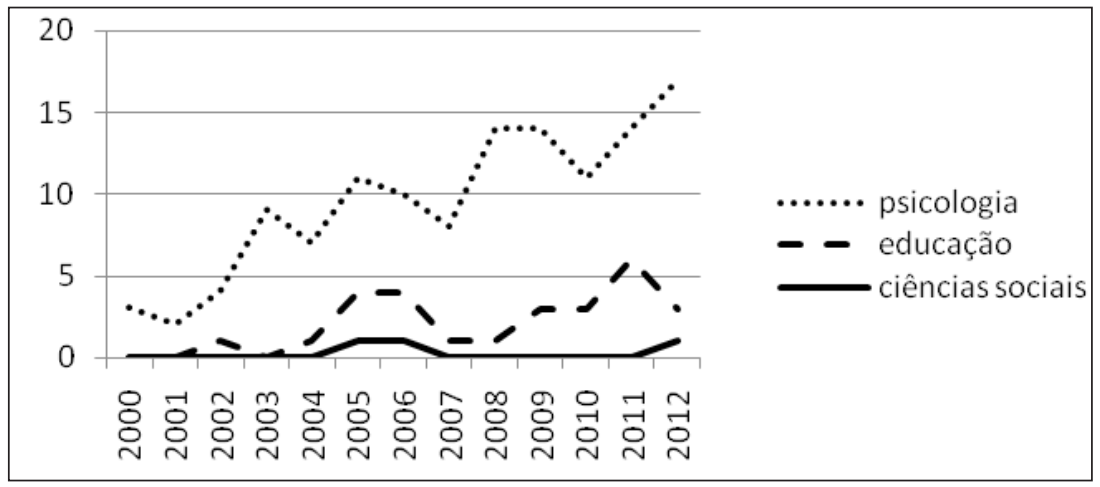

FONTE: Prado (2014).

Nem todas as áreas envolvem crianças na produção de seus estudos e nem todas as crianças são chamadas a participar das pesquisas que pretendem incluí-las. As pesquisas com o envolvimento de crianças aqui analisadas concentram-se geograficamente nas regiões Sudeste e Sul do país, acompanhando a tendência observada em relação à produção acadêmica brasileira em geral. (NASCIMENTO et al., 2013; SILVA; LUZ; FARIA FILHO, 2010). Elas são desenvolvidas prioritariamente na região Sudeste $(42,5 \%)$, mas também são significativos os percentuais de pesquisas nas regiões $\operatorname{Sul}(19,5 \%)$ e Nordeste (17,9\%). As regiões Norte $(1,1 \%)$ e Centro-Oeste $(4,5 \%)$, por outro lado, estão sub-representadas no corpus enquanto lócus de pesquisa. De acordo com esses dados, crianças da região Sudeste estiveram 38 vezes mais envolvidas em pesquisas do que as da região Norte do país.

É importante observar também a reduzida distribuição geográfica pelas unidades federativas. Assim, por exemplo, as pesquisas desenvolvidas na região Norte referem-se apenas ao estado do Pará; $66,7 \%$ das pesquisas do Centro-Oeste referem-se ao Distrito Federal; 61,8\% das pesquisas da região Sul foram desenvolvidas no Rio Grande do Sul; 57,9\% das pesquisas do Sudeste foram realizadas em São Paulo e outros 26,3\% no estado do Rio de Janeiro. A consequência da distribuição pouco dispersa das pesquisas relatadas entre as unidades federativas é a sua ausência em 11 estados brasileiros: Acre, Alagoas, Amapá, Amazonas, Goiás, Maranhão, Mato Grosso, Piauí, Rondônia, Roraima e Tocantins.

Nota-se também a concentração dos artigos em relação aos locais em que as pesquisas com crianças são desenvolvidas: os estabelecimentos educacionais correspondem a $43 \%$ dos artigos (excluídos os que omitem o local da pesquisa). 
Tal resultado coincide com os encontrados em outros levantamentos bibliográficos, como o de Martins Filho e Martins (2012), que tomou como fonte os relatos de pesquisas com crianças apresentados nas reuniões da Associação Nacional de Pós-Graduação e Pesquisa em Educação (ANPEd). O risco, como alertam pesquisadores dos estudos sociais da infância, é as crianças permanecerem enquadradas no lugar de "alunas" e as escolas continuarem sendo tomadas como o local adequado, por excelência, para a presença das crianças.

As investigações sobre infância, como afirma Delalande (2011), não se desconectam do lugar de onde extraem o seu material e a escola é um local intensamente controlado por adultos. Mesmo considerando, como a autora, que a escola não seria o que é sem a contribuição das crianças enquanto atores sociais, as restrições da concentração de pesquisas neste tipo de instituição, nos parece, devem ser ponderadas. O que se torna ainda mais relevante se levarmos em conta que as pesquisas realizadas em instituições educacionais privilegiam a inserção em sala de aula: somente uma delas foi desenvolvida no pátio escolar e apenas $16,9 \%$ realizaram-se também no parque ou no pátio.

Como era de se esperar, as creches e as escolas são os locais escolhidos principalmente quando os autores dos artigos são pedagogos: $70,8 \%$ dos artigos escritos por eles relatam pesquisas em creches ou escolas. Entre os artigos de autoria de psicólogos, a taxa cai para $36,1 \%$, e locais como hospitais ou serviços de saúde (17,5\%), consultórios (10,3\%) e abrigos $(9,3 \%)$ concentram percentuais significativos de pesquisas. Os artigos de autoria de cientistas sociais, por sua vez, dividem-se, quanto ao local da pesquisa, entre instituição de cumprimento de medida socioeducativa, rua ou espaço público e vara da infância e juventude.

A despeito de a população de crianças e adolescentes que vive em áreas rurais no país corresponder a quase $20 \%$ do total de brasileiros deste segmento etário, totalizando 10.403.632 (IBGE, 2011), apenas nove (5,0\%) dos 179 artigos analisados relatam pesquisas desenvolvidas com crianças em contexto não urbano. Entre eles, o local priorizado para a pesquisa é a rua ou outros espaços públicos (4 artigos). Vale observar que nenhum dos artigos relata pesquisa desenvolvida com crianças indígenas.

Ainda buscando responder à pergunta sobre quem são as crianças envolvidas nas pesquisas, procurou-se verificar suas idades. Tal verificação se deu por dois diferentes caminhos: a distribuição dos artigos por idade das crianças (o artigo como unidade); e a distribuição das idades por frequência de aparição nas amostras reportadas nos artigos (a idade como unidade). No primeiro caminho, buscou-se classificar os artigos de acordo com a idade das crianças, tendo como referência as faixas etárias estipuladas para cada nível de ensino: 0 a 2 anos de idade correspondendo à creche, 3 a 5 correspondendo à pré-escola, 6 a 10 correspondendo à primeira etapa do ensino fundamental, 11 a 14 correspondendo 
à etapa final do ensino fundamental e mais de 15 correspondendo ao ensino médio. Muitos artigos, no entanto, como era de se esperar, não se ativeram a tal distribuição e o percentual de faixa etária mista identificado entre as pesquisas relatadas foi bastante alto $(52,0 \%)$, o que dificultou a comparação dos artigos em relação a este aspecto.

De qualquer forma, excluindo os artigos nos quais essa categoria foi classificada como mista (por exemplo, os que caracterizam as idades das crianças como "até 10 anos" ou "a partir de 3 anos") e também aqueles que não apresentaram informações sobre as idades das crianças $(7,3 \%)$, foi possível observar uma concentração maior de pesquisas com crianças de idade entre 6 e 10 anos (42,5\%), além de uma baixa incidência de pesquisas com participantes com mais de 15 anos (6,8\%). Antes de concluir que esse grupo esteja pouco representado, é preciso considerar que é provável que muitos artigos que relatam pesquisas com participantes de mais de 15 anos não tenham sido capturados nas buscas com os descritores "criança" e "infância". Para esse grupo, "adolescência" ou "juventude" seriam descritores mais eficientes.

A outra forma adotada para analisar a idade das crianças participantes das pesquisas inspirou-se em McNamee e Seymour (2012). Os autores buscaram responder quem seriam as crianças representadas pelos estudos sociais da infância, analisando, para isso, a idade das crianças nos artigos publicados por três dos principais periódicos sobre infância (Childhood, Children's Geographies e Children and Society). As mesmas dificuldades encontradas aqui foram observadas por eles: muitos artigos não informam a idade das crianças e outros trazem intervalos tão amplos de idade ("entre 4 e 15 anos", por exemplo) que impossibilitam saber ao certo quantos anos as crianças, de fato, tinham na data da pesquisa. A forma encontrada pelos autores para resolver tal dificuldade foi apresentar não o número de crianças em cada grupo de idade pesquisado, mas o potencial de cada grupo ser incluído nas pesquisas que se basearam nas amostras descritas pelos artigos analisados. Em outras palavras, McNamee e Seymour (2012) consideraram como uma unidade cada ano dos intervalos de idade apresentados. Um estudo, por exemplo, que informasse que a idade das crianças era de até 4 anos, teria seus dados contabilizados nas colunas referentes à idade das crianças no zero, no um, no dois, no três e no quatro; outro estudo que apresentasse um intervalo de idade entre 11 e 13 anos, computaria uma unidade para o 11, outra para o 12 e outra ainda para o 13. Esta forma de medição permite o exame da distribuição dos grupos de idade potencialmente privilegiados em relação aos demais. Procedendo dessa maneira, McNamee e Seymour encontraram uma hiper-representação do grupo de crianças entre 10 e 12 anos entre os artigos analisados. 
A concentração por faixa etária foi também observada aqui (Figura 3). O pico das idades reportadas em nosso corpus está entre 7 e 10 anos, e a idade de 9 anos é a mais presente nas amostras das pesquisas relatadas. Ao que parece, crianças de 9 anos têm duas vezes mais chances de serem incluídas nas pesquisas do que outras de 14 anos, ou mais de quatro vezes mais chances do que crianças de 3 anos.

FIGURA 3 - DISTRIBUIÇÃO DA IDADE DAS CRIANÇAS CONFORME DESCRIÇÃO DAS AMOSTRAS NOS ARTIGOS

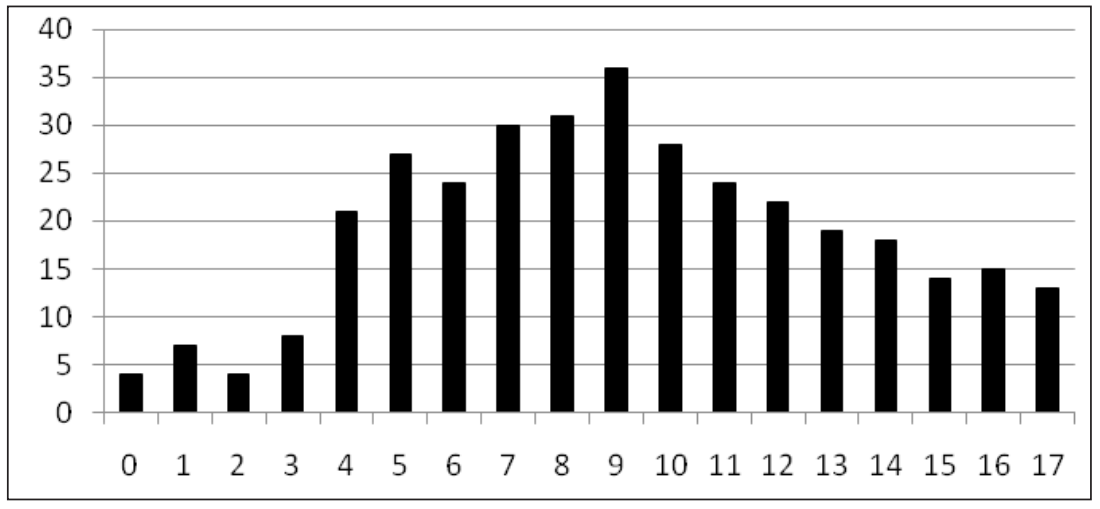

FONTE: Prado (2014).

Como se vê, as crianças pequenas são sub-representadas nas pesquisas relatadas no corpus. Apesar disso, é preciso dizer que aqui elas aparecem muito mais do que entre os artigos analisados por McNamee e Seymour (2012), nos quais sua presença foi praticamente inexistente. As explicações para as diferenças encontradas nas duas pesquisas talvez possam ser atribuídas às diferenças entre o contexto brasileiro, enfatizado por esta pesquisa, e o internacional, analisado por McNamee e Seymour (2012). Elas podem ser atribuídas também à pouca atenção dada aos bebês pelos estudos sociais da infância, conforme Rosemberg (2008) apontava. A pesquisa de McNamee e Seymour (2012) estabeleceu como recorte artigos publicados em revistas reconhecidas pela publicação de pesquisas dos estudos sociais da infância. A pesquisa aqui relatada, ao contrário, não se restringiu à análise de produções desse campo. Com efeito, em nosso corpus, os artigos que relatam pesquisas com crianças de 0 a 2 anos não fazem qualquer referência aos estudos sociais da infância e todos eles são de autoria de psicólogos. Entre as pesquisas desenvolvidas junto a crianças de 3 a 5 anos, há algumas referências $(27,3 \%)$ a esse campo de estudos. Elas também contam 
com a participação expressiva de autores psicólogos (71,4\%), mas a participação de pedagogos é significativa (50\%) e um dos artigos foi escrito em coautoria com um cientista social.

Assim, partindo dos artigos aqui analisados, é possível afirmar que os bebês continuam sendo objeto (e sujeitos) de pesquisas apenas na área da psicologia e, entre essas pesquisas, o diálogo com os estudos sociais da infância permanece ausente.

Apesar de uma extensa produção recente sobre infância advogar pelo reconhecimento das competências das crianças - independentemente de suas idades -, em vez de focalizar seus estágios de desenvolvimento (ABRAMOWICZ; OLIVEIRA, 2011; LEE, 2010; entre outros), o que se observa na produção brasileira aqui analisada é que a prática de pesquisas com elas tem favorecido a escuta de crianças mais velhas. Ao refletir sobre as idades das crianças envolvidas nas pesquisas em contexto internacional, Beazley e colaboradores (2009) centram suas análises na capacidade dos adultos de escutá-las, e não na das crianças de informarem: "[...] é mais fácil para a maior parte das pessoas pensar em pesquisas com crianças entre 10 e 17 anos do que com as pequenas. Trabalhar com as crianças menores requer habilidades e parâmetros que são dispensáveis com crianças maiores". (BEAZLEY et al., 2009, p. 368).

Outros aspectos analisados sobre a caracterização das crianças foram sexo, classe social e raça/etnia. Nota-se uma prevalência de meninos entre as crianças participantes das pesquisas relatadas. Dos artigos (148) que apresentam informações sobre o sexo das crianças envolvidas, $66,9 \%$ relatam pesquisas com meninos e meninas, $20,3 \%$ apenas com meninos e $12,8 \%$ apenas com meninas. Há, portanto, uma diferença de quase $8 \%$ entre os artigos que escutaram apenas meninos e os que escutaram apenas meninas, o que talvez possa ser parcialmente explicado pela abordagem por alguns artigos (sete) de dois temas que predominantemente se relacionam aos meninos: autismo e ato infracional.

Em relação à classe social das crianças que participaram das pesquisas, $40,2 \%$ dos artigos não trazem informações. Entre os artigos que a especificam (107), a maior parte (59,8\%) desenvolveu pesquisas com crianças das camadas populares. Os artigos que menos apresentam informações a esse respeito são os de autoria de pedagogos $(50 \%)$, seguidos pelos escritos por psicólogos $(38,5 \%)$ e por cientistas sociais $(18,2 \%)$.

Bem menos mencionado foi o atributo cor/raça: apenas 13 artigos (7,3\%) trazem informações acerca da pertença étnico-racial das crianças que participaram das pesquisas. Eles informam, em geral, que crianças de diferentes pertenças raciais fazem parte do grupo pesquisado ( 9 artigos), mas há também pesquisas realizadas apenas com crianças brancas, apenas com crianças negras e com uma criança nissei. Considerando os estudos que apontam para a raça como um 
dos eixos de subordinação das sociedades contemporâneas, surpreende o fato de $92,7 \%$ dos artigos não mencionar tal atributo. Cabe ressaltar que a omissão foi identificada em todas as áreas aqui enfatizadas. Faltam informações a esse respeito em $94,3 \%$ dos artigos escritos por pedagogos, em 93,3\% dos artigos de autoria de psicólogos e em $81,2 \%$ dos artigos de cientistas sociais.

\section{Considerações finais}

A análise dos artigos aqui empreendida possibilitou observar que, em larga medida, a escuta de crianças na produção acadêmica brasileira das ciências humanas e sociais é ainda restrita aos âmbitos da psicologia e, em menor grau, da educação. Raros são os artigos de antropólogos ou sociólogos que relatam pesquisas com crianças. Mais raros ainda são os periódicos destas duas áreas que publicam pesquisas com elas. O contexto brasileiro parece diferir-se, portanto, do que se observa em contexto internacional, com sociólogos e antropólogos ocupando posições de relevo na produção acadêmica que reivindica a visibilidade das crianças e a abertura de espaços para a sua voz e para a sua participação.

Nota-se entre a produção acadêmica analisada significativa omissão de informações acerca da caracterização das crianças envolvidas (local da pesquisa, número de crianças, suas idades, pertenças étnico-raciais e classes sociais). Isto surpreende ainda mais se for levado em conta que os artigos analisados foram publicados por revistas consideradas de elevada qualidade e escritos por autores com alta titulação.

Ao que parece, as crianças são hoje mais ouvidas por pesquisadores do que eram no passado. Observa-se, no entanto, uma lacuna nos artigos analisados. Nossa investigação sugere que as vozes ouvidas pelas pesquisas não são de todas as crianças. Há, no Brasil, muito ainda que se caminhar em direção a uma produção de conhecimento menos restrita a contextos socioculturais historicamente privilegiados, como os centros urbanos das regiões Sudeste e Sul do país. É lugar-comum dizer que o Brasil, por sua extensão, pelo tamanho de sua população, por suas diferentes heranças culturais e históricas, é um país de diversidade e de desigualdade. A produção acadêmica com o envolvimento de crianças aqui analisada parece virar as costas para isso: apenas grupos específicos de crianças vêm sendo escutados, enquanto boa parcela da população infantil continua silenciada em nossas pesquisas, sem que tenhamos acesso às suas lógicas simbólicas próprias. As crianças incluídas nas pesquisas analisadas, em geral, têm entre 7 e 10 anos de idade, vivem em áreas urbanas e se localizam nas 
regiões Sudeste e Sul do país. Que outras perspectivas crianças pequenas ou que vivem em áreas não urbanas ou ainda que moram nas regiões Norte, Nordeste ou Centro-Oeste trariam para essas (e para outras) pesquisas? Muito pouco se sabe.

E o que dizer de diferentes perspectivas que poderiam nos ser apresentadas por crianças em contextos menos marcados pela assimetria entre adultos e crianças? As pesquisas com elas continuam a ser realizadas preferencialmente em escolas e creches e, em geral, na própria sala de aula, tendo as crianças enquadradas na condição de alunas.

Ainda que as crianças como atores sociais legítimos passem para o primeiro plano da análise no âmbito da produção acadêmica, elas não necessariamente terão transformadas suas condições concretas de existência na vida cotidiana. Como afirma Thompson (2002, p. 92), “[...] seria muito enganador sugerir que as relações sociais são sustentadas, ou que a ordem social é reproduzida, [...] unicamente através da mobilização do sentido nas formas simbólicas", entre as quais se incluem as produções acadêmicas. Mas, como continua o autor, a mobilização de sentidos abrange, sim, algumas das maneiras como as relações sociais são produzidas e sustentadas. A produção acadêmica participa da constituição da agenda de políticas públicas e pode exercer papel significativo sobre modos de lidar com a infância e com as crianças. Reafirma-se, assim, ao final deste estudo, a responsabilidade que temos enquanto pesquisadores (e adultos), em uma sociedade que se quer mais plural e menos desigual, de abrir espaços para que crianças dos diferentes contextos socioculturais sejam mais e mais ouvidas e tenham suas perspectivas e seus interesses mais e mais considerados.

\section{REFERÊNCIAS}

ABRAMOWICZ, A.; OLIVEIRA, F. As relações étnica-raciais e a sociologia da infância no Brasil: alguns aportes. In: BENTO, M. A. S. (Org.). Educação infantil, igualdade racial e diversidade: aspectos políticos, jurídicos e conceituais. São Paulo: CEERT, 2011. p. 47-64.

BARDIN, L. Análise de conteúdo. Lisboa: Edições 70, 2002.

BEAZLEY, H.; BESSELL, S.; ENNEW, J.; WATERSON, R. The right to be properly researched: research with children in a messy, real world. Children's Geographies, v. 7, n. 4, p. 365-378, 2009.

CASTRO, L. R.; BESSET, V. L. (Org.). Pesquisa-intervenção na infância e juventude. Rio de Janeiro: Trarepa/FAPERJ, 2008. 
CORSARO, W. A. Entrada no campo, aceitação e natureza da participação nos estudos etnográficos com crianças pequenas. Educação e Sociedade, v. 24, n. 91, p. 443-464, 2005.

DELALANDE, J. As crianças na escola: pesquisas antropológicas. In: MARTINS FILHO, A. J.; PRADO, P. D. (Org.). Das pesquisas com crianças à complexidade da infância. Campinas: Autores Associados, 2011. p. 61-80.

DELGADO, A. C. C.; MARCHI, R. C. La petite souris: reflexões em torno de uma socio-antropologia da infância. Momento, Porto Alegre, v. 18, p. 89-97, 2007.

FARIA, A. L. G.; DEMARTINI, Z. B. F.; PRADO, P. D. Por uma cultura da infância: metodologias de pesquisa com criança. Campinas: Autores Associados, 2009.

FREIRE, P. Criando métodos de pesquisa alternativa: aprendendo a fazê-lo melhor através da ação. In: BRANDÃO, C. R. Pesquisa participante. São Paulo: Brasiliense, 1981.

HUTCHBY, I.; MORAN-ELLIS, J. Situating Children's Social Competence. In: HUTCHBY, I.; MORAN-ELLIS, J. (Org.). Children and social competence: arenas of action. London: Falmer Press, 1998.

IBGE. INSTITUTO BRASILEIRO DE GEOGRAFIA E ESTATÍSTICA. Sinopse do Censo Demográfico 2010. Rio de Janeiro: IBGE, 2011.

JAMES, A. Giving voice to children's voices: practices and problems, pitfalls and potentials. American Anthropologist, v. 109, n. 2, p. 261-272, 2007.

JAMES, A. Agency. In: QVORTRUP, J.; CORSARO, W.; HONIG, M. The Palgrave handbook of childhood studies. Basingstoke, Hampshire: Palgrave Macmillan, 2009. p. 34-45.

JAMES, A.; PROUT, A. Introduction. In: JAMES, A.; PROUT, A. (Org.). Constructing and reconstructing childhood: contemporary issues in the Sociological study of childhood. New York: RoutledgeFalmer, 1997. p. 1-7.

JENKS, C. Constituindo a criança. Educação, Sociedade \& Cultura, Revista da Associação de Sociologia e Antropologia da Educação, n. 17, p. 185-216, 2002.

LEE, N. Vozes das crianças, tomada de decisão e mudança. In: MÜLLER, F. (Org.). Infância em perspectiva: políticas, pesquisas e instituições. São Paulo: Cortez, 2010. p. 42-64.

MARTINS FILHO, A. J.; MARTINS, A. C. F. A complexidade da infância: balanço de uma década de pesquisa com crianças apresentadas na ANPEd. In: DORNELLIS, L.; FERNANDES, N. (Org.). Perspectivas sociológicas e educacionais em estudos da criança. Braga: Centro de Investigação em Estudos da Criança, Universidade do Minho, 2012.

MARTINS FILHO, A. J.; PRADO, P. D. (Org.). Das pesquisas com crianças à complexidade da infância. Campinas: Autores Associados, 2011.

MASON, J. Child research towards 2015: a global scenario. Childwatch International Key Institutions Assembly, Hurdal, Noruega, jun. 2005. 
MCNAMEE, S.; SEYMOUR, J. Towards a sociology of 10-12 years old? Emerging methodological issues in the 'new' social studies of childhood. Childhood, v. 20, n. 2, p. 156-168, 2012.

MÜLLER, F. (Org.). Infância em perspectiva: políticas, pesquisas e instituições. São Paulo: Editora Cortez, 2010.

NASCIMENTO, M. L.; BREDA, B.; SERRÃO, C.; SAMORI, D.; ALBOZ, L.; GOMES, L. O.; CORREIA, M. A.; PRADO, R. L. C.; ALMEIDA, R.; KLEIN, S. Infância e Sociologia da Infância: entre a invisibilidade e a voz. São Paulo: FEUSP, 2013.

PRADO, R. L. C. A participação de crianças em pesquisas brasileiras das ciências sociais e humanas. Tese (Doutorado em Psicologia Escolar e do Desenvolvimento Humano) Instituto de Psicologia da Universidade de São Paulo, São Paulo, 2014.

PRADO, R. L. C. Trabalho infantojuvenil em artigos acadêmicos de psicólogos: uma interpretação ideológica. Estudos de Psicologia, Campinas, v. 30, n. 1, p. 101-110, jan./ mar. 2013.

PROUT, A. Participação, políticas e as condições da infância em mudança. In: MÜLLER, Fernanda (Org.). Infância em perspectiva: políticas, pesquisas e instituições. São Paulo: Cortez, 2010.

QVORTRUP, J. A tentação da diversidade - e seus riscos. Educação e Sociedade, Campinas, v. 31, n. 113, p. 1121-1136, out./dez. 2010.

ROSEMBERG, F. Crianças e adolescentes na sociedade brasileira e a Constituição de 1988. In: OLIVE, R. G.; RIDENTI, M.; BRANDÃO, G. M. (Org.). A Constituição de 1988 na vida brasileira. São Paulo: Aderaldo \& Rothschild: Anpocs, 2008. p. 296-333.

SILVA, I. O.; LUZ, I. R.; FARIA FILHO, L. M. Grupos de pesquisa sobre infância, criança e educação infantil no Brasil. Revista Brasileira de Educação, v. 15, n. 43, p. 84-98, 2010.

SIROTA, R. Emergência de uma sociologia da infância: evolução do objeto e do olhar. Cadernos de Pesquisas, n. 112, p. 7-31, mar. 2001.

THOMPSON, J. B. Ideologia e cultura moderna: teoria social crítica na era dos meios de comunicação de massa. 6. ed. Petrópolis: Vozes, 2002.

Texto recebido em 23 de agosto de 2016. Texto aprovado em 03 de novembro de 2016. 